\title{
AQUILES: O HERÓI ÉPICO E O PRENÚNCIO DE ELEMENTOS TRÁGICOS
}

\author{
João Milton Walter Tavares \\ Doutorando em Psicologia Clínica e Cultura pela Universidade de Brasília (UNB) \\ joao_milton@hotmail.com \\ Paulo José da Costa \\ Doutor em Psicologia Clínica pela Universidade de São Paulo (USP) \\ Professor adjunto de Psicologia da Universidade Estadual de Maringá (UEM) \\ Coordenador do Grupo de Estudos e Pesquisas em Psicanálise e Desenvolvimento \\ Humano - CNPq-UEM \\ pjcosta@uem.br
}

\section{RESUMO}

O presente artigo tem por objetivo discutir elementos trágicos prenunciados na obra de Homero, a llíada, principalmente por meio do herói Aquiles. Abordamos inicialmente a relação de Aquiles com o tema da morte e como influenciou na decisão do herói em se afastar dos campos de batalha e, posteriormente, decidir por retornar com a finalidade de vingar Pátroclo. A llíada tem por objetivo cantar a cólera de Aquiles, seus feitos e consequências. Trabalhando a questão trágica presente nas linhas da epopeia é possível identificar pontos que já estavam presentes nas obras literárias séculos antes do movimento trágico que ocorreu no século $\mathrm{V}$ a.c. na cidade de Atenas. Apresentamos aqui o Aquiles trágico que está contido na narrativa homérica.

Palavras-chave: tragédia, Homero, Aquiles, herói, trágico.

\section{ABSTRACT}

This article aims to discuss tragic elements foreshadowed in Homer's Iliad, mainly by means of the hero Achilles. We initially addressed the Achilles' relationship with the theme of death and how it influenced the hero's decision to move away from the battlefields and then his decision to return for the purpose of avenging Patroclus. The lliad aims to sing Achilles' wrath his achievements and its consequences. Working the tragic question presented in the lines of the epic it is possible to identify points that were already existing in literary works centuries before the tragic movement that occurred in the fifth century a.c. in the city of Athens. Here we present the tragic Achilles that is contained in the Homeric narrative.

Keywords: tragedy, Homer, Achilles, hero, tragic. 


\section{Introdução}

O século $V$ a. C. foi quando a tragédia surgiu em Atenas, na Grécia. Foi um movimento cultural sui generis que produziu valiosas peças teatrais. As tragédias trabalharam com uma nova figura do herói que contrastava com aquele da epopeia. 0 herói trágico não goza de toda a glória adquirida por seus feitos, não é um modelo a ser seguido, é marcado por uma severa punição devido às suas ações. Muitos heróis cantados nas epopeias foram utilizados nas tragédias justamente por serem amplamente conhecidos pela população de Atenas daquele tempo. Utilizando estes heróis para representar algo inédito até então, os tragediógrafos apresentaram ao público ateniense a narrativa trágica, que segundo Aristóteles (2004) ela deve seguir um esquema definido, isto é, a tragédia deve seguir no sentido da felicidade para o infortúnio e o final da tragédia deve ser necessariamente marcado pela infelicidade. Ainda de acordo com Aristóteles, a ação trágica da peça é sempre desencadeada por uma falha cometida pelo herói.

Aquiles é o principal herói da llíada, de Homero, uma epopeia clássica. Toda epopeia tem por finalidade cantar os feitos heroicos, exaltar as qualidades mais altivas dos heróis, e estes, geralmente de ascendência divina, realizam grandes feitos dignos de serem eternizados nas páginas do tempo. É o caso da llíada que narra feitos extraordinários de grandes heróis passados no último ano da guerra de Tróia. Pinheiro (2011) nos revelou que, nessa obra, embora seja um poema épico, se evidenciam certos aspectos trágicos no herói Aquiles, séculos antes da primeira tragédia ser escrita. O herói é fadado a sofrer a partir de suas escolhas nas linhas de Homero, sendo o principal exemplo a ocasião da morte de seu companheiro Pátroclo, morto pelas mãos de Heitor. 
Sendo assim, o objetivo deste artigo é discutir o trágico prenunciado nas linhas da llíada através de Aquiles, o maior dos heróis gregos na poesia homérica.

\section{O herói trágico}

O herói trágico busca a verdade em si, quer compreender quem é e qual é seu lugar no mundo. É transgressor de seus limites e se depara com as consequências de suas ações que o colocam frente a frente com o seu verdadeiro eu. As ações do herói o levam uma autorreflexão sobre sua natureza, proporcionando uma lucidez sobre si. A llíada ainda não traz explicitamente este movimento de descoberta sobre si no herói, como ocorre nas tragédias, mas, como já nos alertou Lesky (1996) nas epopeias homéricas é possível encontrar aspectos que virão a se desenvolver nos séculos posteriores e culminarão na tragédia.

Lesky (1996) aponta que as características que definiriam o que seria uma tragédia já estavam em caráter germinal nas epopeias. E, para o autor, a genialidade da llíada é colocar no centro do conjunto da obra a ira de Aquiles, como já anunciado nos primeiros versos da obra: "Canta, ó deusa, a cólera de Aquiles, o Pelida / (Mortífera!..." (HOMERO, 2013, p. 109), tornando assim o herói uma figura que evidencia elementos trágicos, que irá conquistar e perder devido à sua cólera. O momento específico que podemos considerar o início da ação trágica, isto é, da ascensão e declínio do herói, se passa no canto $\mathrm{XI}$, quando Aquiles está recolhido em seu navio olhando ao longe o avanço troiano e chama Pátroclo. E "ele ouviu e saiu da tenda / igual a Ares - o que para ele foi o início da desgraça" (HOMERO, 2013, p. 356). O termo desgraça se refere à morte de Pátroclo que ocorrerá pelas mãos de Heitor em breve. Um outro entendimento que podemos ter é 
que aí começa a desgraça de ambos: de Pátroclo, porque irá sem Aquiles para a linha de frente da batalha, triunfará inicialmente afastando o perigo inimigo das proximidades do acampamento, mas, dominado por um furor, não cumpre a orientação dada a ele por Aquiles e avança em direção a Tróia, momento que será morto; de Aquiles, já que a morte de Pátroclo é a motivação para a escolha trágica que o herói fará. Mesmo sabendo das consequências de sua ação, decide participar das batalhas e comanda o exército grego na linha de frente, fazendo o exército troiano recuar para dentro de suas muralhas, enfrenta Heitor e derrota o mais poderoso inimigo. Mas, o destino de Aquiles está traçado; junto com a glória conquistada vem a anunciação de sua inevitável morte. Para os dois a morte é consequência de suas escolhas.

\section{A discussão da morte em Aquiles}

A morte é um tema muito presente na llíada, como é esperado de um épico de guerra, tanto quando se apresenta como um destino temido, como algo presente, é, de fato, concreto e muito próximo dos protagonistas. E quando se trata de Aquiles parece que a morte está sempre às espreitas. Para compreendermos como o herói se relaciona com a morte, vejamos primeiramente como a temática é abordada na obra.

A llíada tem cerca de 250 mortes registradas no decorrer de todo o épico. Alexander (2014) relata que a maioria das mortes que ocorre no texto é de personagens que aparecem na história somente para morrer pelas mãos dos principais heróis da trama. E mesmo neste momento, estes personagens já fadados ao inexorável destino da morte têm suas características ressaltadas, ganhando uma história de vida no momento 
derradeiro da sua existência. O que traz um tom de pessoalidade como vemos no trecho a seguir:

Foi Antíloco o primeiro a matar um homem armado dos Troianos, um valente que combatia na primeira linha: Equepolo, filho de Talísio Primeiro desferiu-lhe um golpe no elmo com crinas de cavalo e pela testa adentro lhe empurrou a lança, além do osso foi a ponta de bronze e a escuridão cobriu-lhe os olhos: tombou em combate mortal como se desmorona uma muralha (HOMERO, 2013, p. 196).

Alexander (2014) fala que não são mortes deliberadas simplesmente para compor um cenário de guerra. Todas as mortes parecem ter o objetivo de mostrar tanto a glória daquele que venceu o duelo quanto a importância de quem morre, narrando sobre sua família, sua história de vida, o identificando e o tornando único. As mortes na obra garantem a humanização dos derrotados. Dessa forma, as mortes ocorridas no decorrer do texto homérico não têm importância somente numérica para nos mostrar o impacto da guerra, mas, traz uma questão qualitativa à tona. Aquele que morreu é insubstituível em suas características (ALEXANDER, 2014).

Podemos perceber como é o cenário de discussão sobre a morte em toda a obra: é a partir do morrer que a história de vida daquele guerreiro é eternizada pelas palavras do poeta, pois suas ações serão cantadas para as próximas gerações. O morrer é o caminho para a glória eterna buscada pelos gregos e troianos nos campos de batalha, é o mecanismo que levará o nome do herói para a eternidade.

Aquiles se vê pensando sobre a morte e a brevidade de sua vida em muitas partes da narrativa. Pinheiro (2011) fala que: 
a essência do trágico pode ser compreendida através das palavras de Goethe, que o define como uma 'contradição inconciliável', insuscetível de ser resolvida por qualquer via, ou seja, o conflito trágico é total e absolutamente insolúvel (PINHEIRO, 2011, p. 89).

E o que seria mais insolúvel do que a própria morte? O reconhecimento por Aquiles de sua mortalidade é o principal dilema imposto ao herói. As habilidades de combate de Aquiles são muito pareadas com alguns deuses, em grandes embates com estes seres imortais, como quando ele luta com Escamandro, o deus-rio. Mas, nenhum dos seus feitos o fará transpor o que separa os homens dos deuses e essa distância é o abismo entre a mortalidade e a imortalidade.

Em diversas vezes por toda a llíada Tétis, mãe de Aquiles, traz em tom fúnebre a discussão acerca do destino de seu filho e de sua morte prematura. Na mortalidade de Aquiles, Alexander (2014) afirma residir as origens da tragédia, algo maior que a própria épica:

Nos antecedentes míticos de Aquiles, um grande poeta poderia discernir possibilidades estimulantes: aqui está um guerreiro ímpar, com uma vida não relacionada à guerra, um solitário e um marginal que não podia ver no esforço militar coletivo nada que dissesse respeito a si mesmo, o mais pungentemente mortal de todos os heróis, cuja atividade era o risco diário das guerras. Aqui está um herói com a natureza e a estatura para pensar e falar como um indivíduo, para se distanciar das convenções heroicas e desafiá-las. Na mortalidade hiperdeclarada de Aquiles encontram-se as origens de algo potencialmente superior até mesmo a épica - e esse algo era a tragédia (ALEXANDER, 2014, p. 139).

Tétis sempre buscou obter a imortalidade para seu filho. Nas diferentes versões sobre a infância de Aquiles, é comumente encontrada a sua quase invulnerabilidade e a 
frustrada tentativa de Tétis em retirar de seu filho a herança do pai, a mortalidade humana. Em todas as versões do mito, Tétis busca proteger seu filho do destino reservado a todos os homens, a morte.

Na obra de Homero encontramos a última tentativa de Tétis de conceder a imortalidade para seu filho, logo após a morte de Pátroclo. Aquiles estava sem armadura, pois a sua estava em posse de Heitor. Tétis pede para ele esperar até o amanhecer quando ela retornaria com uma armadura forjada por Hefesto, o deus ferreiro. Alexander (2014) vê na fala de Tétis a Hefesto um pedido desesperado de uma mãe, que conhecendo o destino de seu filho, procura uma forma de driblar o fatídico fim. Uma armadura mágica que espera ser capaz de desviar o golpe final destinado a ceifar a vida de Aquiles.

A armadura feita por Hefesto para Aquiles é, como pontua Alexander (2014), mais utilizada para ressaltar a mortalidade dele do que para protegê-lo. Hefesto então comunica a Tétis: "Prouvera que eu fosse capaz de assim o esconder longe / da morte dolorosa, quando sobrevier o terrível destino..." (HOMERO, 2013, p. 535). Também é claro para ele, que apesar da sua destreza na confecção da armadura, nada evitará que o implacável destino se cumpra.

De toda a armadura forjada pelo deus para Aquiles, o item que se sobressai é o escudo. Exatos 130 versos são utilizados por Homero para descrevê-lo. Ironicamente, o deus entalhou no escudo aquelas que são as linhas que mais nos fazem fugir do ambiente de guerra que é retratado na obra. Alexander (2014) fala que o deus não colocou no escudo as imagens que são mais associados à guerra, mas, pelo contrário, fez uma descrição de um cenário de paz e tranquilidade, descreveu a vida comum, os frutos colhidos por aqueles que retornam da guerra. A descrição feita por Homero do que foi talhado no escudo de Aquiles é o dia-a-dia do homem grego, seus hábitos e 
rotinas. Aquiles levará talhado em suas armas, tudo aquilo que está abdicando com esta decisão, isto é, o retorno ao cotidiano, à vida comum. O herói é ciente de que, ao optar vingar-se de Heitor pela morte de Pátroclo e de outros companheiros que morreram devido à sua ausência nos combates, estará abrindo mão de toda a vida que conhece. $\mathrm{O}$ escudo é um artefato de defesa na armadura de um guerreiro, mas, no caso de Aquiles, parece ter uma segunda função, mostrar para o seu portador a vida que não poderá ter caso venha a utilizá-lo (ALEXANDER, 2014).

\section{Aquiles e a decisão de retornar à guerra}

A llíada narra os fatos ocorridos em alguns dias do último ano da guerra de Tróia, especificamente, a partir da reclusão de Aquiles depois da discussão com Agamêmnon. Logo nos primeiros cantos da epopeia não vemos o herói em ação na batalha, somente as consequências para o exército aqueu da decisão de Aquiles de se abster de batalhar. Passados poucos dias após a decisão de Aquiles, ocorreu uma reviravolta no campo de batalha. Os troianos, que antes estavam acuados e protegidos por suas muralhas, agora saíram de seus portões e avançam sob a liderança de Heitor, fazendo com que os aqueus recuassem até os próprios navios. Se inicia apressadamente a construção de uma muralha para proteger o acampamento do exército grego, ocorrendo uma inversão de posição.

Zeus declara como será o futuro dos personagens, mesmo que estes ainda não saibam das escolhas que farão:

Pois não desistirá da guerra o temível Heitor / Antes que junto às naus se erga o Pelida de pés velozes, / No dia em que às popas das naus combaterão / No mais terrível aperto em torno de Pátroclo morto, tal como está destinado (HOMERO, 2013, p. 285-286). 
Sabemos o destino dos heróis a partir da fala de Zeus, mas Heitor, ignorante do seu destino, prepara a vigília próximo dos navios inimigos, temendo uma fuga destes durante a noite. Aquiles está com Pátroclo em sua tenda e teve pouca participação até o momento na narrativa. Agamêmnon está reunido com os líderes de seu exército para avaliar a situação em que se encontram. O experiente Nestor recorda que a situação para os gregos começou a piorar a partir da desavença entre Agamêmnon e Aquiles e propõe que este seja presenteado para deixar sua ira de lado e retorne às batalhas.

Aquiles recebe em sua tenda a comitiva formada por Odisseu, Ájax e Fênix. Estes têm o objetivo de aplacar a ira do herói em autoexílio. Ao chegar na tenda, a comitiva encontra Aquiles tocando lira e cantando a kleos, que são canções narrando os feitos de heróis. Alexander (2014) diz que a cena encontrada por Odisseu e seus companheiros demonstra que, neste momento, o herói tinha optado por cantar grandes feitos de outros heróis do que realizar ações para obter sua própria kléos.

Odisseu é o responsável por fazer a oferta em nome de Agamêmnon. Alexander (2014) aponta que, estrategicamente, ele adicionou por sua própria conta, além da oferta feita por Agamêmnon, dois argumentos a mais na tentativa de convencer o herói. Primeiramente apela para o senso de coletividade, pois a reclusão voluntária de Aquiles não prejudica somente Agamêmnon, mas todos aqueles que desembarcaram junto com ele nas planícies troianas. Também adiciona um outro argumento para atacar o orgulho do herói, expondo que Heitor declara não haver nenhum homem que seja páreo para ele entre o exército inimigo. Odisseu parece compreender o tamanho da ira de Aquiles em relação ao líder do exército grego, sabe que não são bens materiais que comprariam o retorno do herói. Era necessário mais, algo que ferisse ainda mais o orgulho de Aquiles do que o próprio Agamêmnon havia ferido. Porém, Aquiles recusa os presentes de forma 
ríspida, em um discurso severo e firme em sua posição, decidido a não retomar sua posição nas batalhas.

Alexander (2014) nos diz sobre esta recusa de Aquiles: "O que quer Aquiles? O afastamento de um herói encolerizado de seu povo é tema clássico tanto de épicos quanto dos contos folclóricos - tema que pressupõe, contudo, o derradeiro apaziguamento e retorno do herói." (p. 127). Homero faz uma ruptura com o que era esperado do épico, o retorno do herói. Deixa claro que a llíada não é simplesmente outra narrativa exaltando os grandes feitos de batalha, outra kléos. Para a autora, Aquiles, ao recusar os presentes oferecidos, está indo contra tudo aquilo que se exaltava em seu tempo. Nada que possa ser oferecido como presente ao herói lhe parece razoável para o custo de sua própria vida, já que havia sido alertado pela sua mãe acerca da escolha que teria que fazer, optando por participar da guerra de Tróia e conhecer a glória ao custo da própria vida, ou se retirar dos campos de batalha e ter muitos anos de vida, mas fadado à mediocridade.

Aquiles, após ter recusado o acordo com Agamêmnon, manteve suas naus atracadas próximas à planície troiana. Não zarpou para Ftia como havia sugerido que faria para Odisseu. Observa de seus navios o desenrolar dos acontecimentos entre os dois exércitos. Vendo um soldado aqueu, que não conseguiu reconhecer, voltando ferido para o acampamento, chama Pátroclo e "... Ele ouviu e saiu da tenda / igual a Ares - o que para ele foi o início da desgraça" (HOMERO, 2013, p. 356). Como já apresentamos, podemos entender que o início da desgraçada é para ambos.

Pátroclo comovido com a situação do exército, pede a Aquiles que o deixe retornar para a batalha e, além disso, que possa usar a armadura pessoal de Aquiles, na tentativa de se passar pelo herói. Aquiles aceita o pedido, lhe dá sua armadura e reúne os 
mirmidões para serem liderados por seu escudeiro. Aquiles fala para Pátroclo retornar ao acampamento após afastar o perigo iminente do exército troiano próximo dos navios.

Todo o canto XVI da llíada se trata da aristéia de Pátroclo. Segundo Alexander (2014), Pátroclo mata cinquenta e quatro troianos em seu avanço, sendo Sarpédon, filho mortal de Zeus, o mais importante dentre eles. A tentativa de se passar por Aquiles e amedrontar o exército liderado por Heitor, funciona inicialmente, mas, em seguida Pátroclo é reconhecido mesmo usando a armadura do companheiro. Depois de ter feito os troianos recuarem para suas próprias muralhas, Pátroclo ignora a ordem de Aquiles de voltar para o acampamento assim que o exército inimigo fosse afastado e continua avançando até o limite da cidade de ílion. Alexander (2014), ao comentar sobre a morte de Pátroclo, relata que Homero manteve certo aspecto da antiga concepção fantástica das histórias, e, a armadura de Aquiles, que deveria tornar qualquer um que a utilizasse invulnerável, foi tirada de Pátroclo por Apolo momentos antes de ser atingido e morto. Então, a sequência dos fatos foi a seguinte. Pátroclo foi atacado inicialmente pelo deus Apolo que retirou dele a armadura de Aquiles deixando-o desprotegido, permitindo que fosse atingido pela lança de um jovem soldado inexperiente. Já ferido, Pátroclo tenta recuar para o meio de seus companheiros, quando Heitor o viu retrocedendo e avançou passando pelas falanges acertando Pátroclo no ventre com sua lança.

A morte de Pátroclo é a mais importante das mortes ocorridas na llíada, pois até a morte de Heitor está ligada a este fato. Aquiles não retornaria aos campos de batalhas por nada que Agamêmnon pudesse oferecer, mas pela morte de seu escudeiro, pela culpa da morte de Pátroclo, ele optou pelo renome eterno em detrimento da longevidade.

\section{4. $O$ despertar do trágico: a cólera de Aquiles}


O tema central da llíada é sem dúvida a ira de Aquiles, e todas as ações que se desencadearam a partir das ações do herói. Alexander (2014) nos diz que a primeira palavra de toda a narrativa é mēnis que significa "ira que se prolonga no tempo, justificada por um desejo de justa vingança" (ALEXANDER, 2014, p. 216), e observa que ela tem um significado mais carregado, mais intenso que outras palavras equivalentes como chólos, kótos que significam raiva e ressentimento, respectivamente.

Quanto à ira de Aquiles, podemos dividir a llíada em dois momentos. O primeiro logo no primeiro canto com a disputa entre Aquiles e Agamêmnon, em que este, devido à sua autoridade, pede que Aquiles Ihe entregue Briseida, seu prêmio de guerra. Aquiles chega a ter o impulso de sacar a arma e atacar Agamêmnon, mas seu furor é apaziguado por Atena, que o faz voltar atrás. Aquiles toma a decisão de se isolar no seu acampamento, se retirando das batalhas juntamente com os seus liderados, os mirmidões. Esta primeira parte se estende até o canto XVI, quando ocorre a morte de Pátroclo. A partir daí temos o segundo momento, que ocorre uma revolução na trama, o percalço com Agamêmnon é superado por Aquiles quando este dirige a Heitor toda a sua ira,

Aquiles ciente da morte de Pátroclo pelas mãos de Heitor decide retornar a batalha para vingar seu amigo. O que Alexander (2014) denominou de a decisão trágica de Aquiles. Vemos um herói determinado na vingança. Tamanha a dor sentida que é insuportável, o sentimento não é possível de ser explicado, nesse momento é somente sentido. Aquiles sabe o que sofre em seu peito e sabe o que tem que fazer para aliviar sua dor. Tudo o que Ihe interessa agora é matar Heitor, pois foi ele quem trouxe tamanha desgraça. O desejo de vingança é maior que o desejo de viver de Aquiles. Veste a 
armadura trazida por sua mãe como um ritual para as ações que tomará daqui para frente.

Nos dois momentos a ira de Aquiles é devastadora, ora para os gregos, ora para os troianos. Na divisão que propomos, inicialmente Aquiles se abstêm da ação, opta pelo não agir. Os desdobramentos dessa reclusão do herói são enormes para seus aliados. Os troianos, que com a presença de Aquiles, não se arriscavam longe de suas protetoras muralhas, com a retirada do herói chegam até mesmo a incendiar alguns dos navios atracados. Heitor aproveita esse enfraquecimento do exército inimigo e mostra o seu melhor na liderança do exército troiano. A muralha, construída por Agamêmnon para proteger o acampamento e os navios, foi facilmente superada com a liderança de Heitor. O caos se instalou no exército grego. Heitor, sem o rival no exército inimigo, está livre para agir como bem entender, já que não há ninguém de igual capacidade em batalha atuando no momento. Homero nos alerta que "Ninguém poderia agora detê-lo, a não ser / os deuses..." (HOMERO, 2013, p. 380), já que neste momento Aquiles não é uma opção para deter o avanço de Heitor. O príncipe troiano, além de derrubar os portões que protegiam o acampamento, lidera todo o exército de seu pai que não vacila em segui-lo. A cólera de Aquiles, neste primeiro momento, se dá pela ausência.

Já o segundo momento, a ira do filho de Peleu é marcado pela ação. Aquiles assume, de forma natural, a liderança do exército grego. Quando veste a sua armadura e toma suas armas, Homero nos diz: "Como asas Ihe serviam as armas: levantava o pastor do povo!" (HOMERO, 2013, p. 554). Agora se levanta uma liderança que fará frente a Heitor, alguém que tem habilidades suficientes para frear um exército em pleno avanço, e mais, fazê-lo recuar. A aristéia de Aquiles. 
'Tolo! Não me ofereças resgates nem regateies comigo.

Antes de a Pátroclo ter sobrevindo o dia do seu destino, sempre me era mais agradável ao espírito poupar os Troianos; e muitos levei eu vivos para vender noutro lado. Mas agora nem um fugirá à morte, de todos os que o deus me lançar nas mãos à frente das muralhas de Ílion: nem um dentre todos os Troianos, muito menos os filhos de Príamos. Não, querido amigo: morre tu também. Por que horas para nada? Também morreu Pátroclo, que era muito melhor que tu. E não olhas para mim e não vês como sou alto e belo? Homem nobre é meu pai e deusa é a mãe que me gerou. Mas também para mim virá a morte e o fado inelutável. Chegará a aurora, a tarde ou então ao meio-dia em que em combate alguém me privará da vida, quer atirando a lança ou disparando uma flecha.' Assim falou; e deslassaram-se os joelhos e o coração do outro. Largou a lança, mas pôs-se de joelhos com ambos os braços estendidos. Aquiles desferiu-lhe um golpe com a espada afiada na clavícula, por baixo do pescoço; e a espada de dois gumes penetrou (HOMERO, 2013, p. 578-579).

Aqui vemos um herói ativo, e o que causa a destruição é a própria ação de Aquiles. No trecho acima, temos uma ideia dessa mudança de atitude e como se tornou cruel diante do inimigo. O desejo de vingança faz o filho de Peleu matar impiedosamente seus inimigos, mesmo quando este já está ajoelhado em sua frente, sem arma para defesa.

A cólera de Aquiles atinge a todos, é vingativa e destrutiva, ora através da ausência, ora através da presença. Podemos pensar que a implacável fúria do herói se aproxima de uma fúria divina, pois todos os envolvidos na guerra de Tróia são impactados pelas suas consequências, inclusive os deuses. 


\section{O Aquiles trágico}

Para Aquiles, a decisão de participar da campanha contra a cidade de Tróia é bastante antiga. Tétis, conhecendo o destino que era reservado para seu filho em Tróia, antes que Odisseu e outros heróis chegassem até ele para recrutá-lo para a guerra, o escondeu entre as mulheres de Esquiro. Lá, Aquiles, disfarçado de mulher, passou a se chamar Pirra, devido aos seus cabelos avermelhados. Tamanha era a beleza do herói que, quando Odisseu e Diomedes foram até a ilha buscá-lo, não conseguiram identificá-lo entre as mulheres. Para conseguir reconhecer o herói, Odisseu e Diomedes levaram entre os presentes que seriam oferecidos para as mulheres alguns armamentos. Somente uma delas, Pirra, se interessou pelas armas. Assim Aquiles foi persuadido a seguir com a campanha formada para a guerra. A dúvida sobre enfrentar o destino que o esperava nas planícies de Tróia já existia em Aquiles antes do primeiro navio zarpar. E esta decisão que deve ser tomada pelo herói o acompanha durante a primeira metade de toda a llíada. E é nesta escolha que se encontra o erro trágico em Aquiles.

Todo herói incorrerá na escolha trágica, e é a hýbris que encontramos no personagem que faz com o que ele cometa o erro trágico. Pastore (2012) fala que na narrativa grega nada acontece sem a vontade dos deuses, eles sempre participam e estão cientes das consequências dos atos do herói, e muitas vezes, são os próprios deuses que atuam de forma a levá-lo a incorrer em hýbris para que, assim, ele chegue ao erro trágico. Mas, se por um lado os deuses pactuam com a ação na narrativa, pelo outro lado, "nada tampouco acontece sem a participação e o engajamento do homem" (PASTORE, 2012, p. 108). Apesar do destino ser inescapável para o herói trágico, ele tem uma participação ativa no rumo dos acontecimentos. 
Mas afinal de que se constitui esta culpa atribuída ao herói? E este erro que é essencial para a tragédia, como nos disse Aristóteles, e vai além da falta moral, como podemos entender o seu significado? Pastore (2012) afirma que o sentido do trágico se faz na dualidade, pois o herói é formado por sentimentos opostos, situando-se entre a culpa e a inocência, a lucidez e a cegueira, a loucura e a sanidade, sendo composto pelo inconciliável.

O herói é inconsciente daquilo que é, e a ele é negado a abstenção desta contradição que o define. Acaba impulsionado a cometer uma falha que trará consequências e que será responsabilizado; portanto, o herói trágico na mitologia grega é guiado por caminhos desconhecidos por ele. O herói de uma tragédia vive, através da hýbris, a experiência trágica que é o excesso, o atravessar limites impostos aos homens e se aproximar daquilo que é exclusivo das divindades, o desejo pela transgressão (PINHEIRO, 2012). O herói transita em dois mundos, o humano e o divino. O primeiro de caráter normativo, fadado aos mortais; já o segundo é transgressor, sem regras ou limites, exclusivo para os imortais. O herói, ao se aventurar por estes dois mundos, vive o paradoxo: ao mesmo tempo em que ele é obrigado a seguir as regras, tem o ímpeto de transgredi-las. Aquiles, ao confrontar Agamêmnon, está fazendo um desafio à hierarquia, como nos mostrou Alexander (2014). Ele se vê com o mesmo direito que Agamêmnon, mesmo este sendo um rei. Tal ato demonstra o impulso a transgressão por parte de Aquiles, se rebelar contra o rei é ir contra o status quo daquele arranjo social que se está inserido.

A guerra de Tróia teve a duração de dez anos, e como já sabemos, a llíada retrata alguns dias do último ano da guerra. Apesar das habilidades de Aquiles sempre terem sido destacadas na arte da guerra e do herói ter participado das batalhas desde o início 
do cerco à cidade de Tróia, durante os nove primeiros anos a batalha entre gregos e troianos não teve grandes avanços. A Ilíada começa sua narrativa justamente no momento em que a guerra troiana começa a ganhar um desfecho. Entendemos que na agressividade excessiva presente em Aquiles é que o filho de Peleu apresentou as características esperadas do herói. Aquiles sozinho realiza o que todo o exército grego foi incapaz de fazer, conseguindo combater todo o exército troiano; ele é empossado com o poder que todo o exército deveria ter. Neste retorno, as habilidades bélicas de Aquiles são dignas de um deus, o herói se aproxima demasiadamente do inacessível para um homem, e, por isso, a punição necessária com a sua morte.

Quando Tétis expõe para seu filho as consequências de uma decisão de ir participar da guerra em Tróia, entendemos que o elemento trágico já está aí anunciado. Aquiles, assim como qualquer herói de uma tragédia grega, é negado usufruir de sua glória, o objetivo maior dos heróis épicos. Quando Aquiles realiza feitos dignos de um herói epico está fadado à morte.

\section{Referências}

ALEXANDER, C. A guerra que matou Aquiles. Tradução de Márcio de Paula S. Hack. Rio de Janeiro: Bertrand Brasil, 2014.

ARISTÓTELES. Poética. Tradução de Baby Abrão. In: Aristóteles. Aristóteles - vida e obra. São Paulo: Nova Cultural, 2004. p. 34-75.

HOMERO. Ilíada. Tradução de Frederico Lourenço. In: Homero. Ilíada. São Paulo: Penguin Companhia das Letras, 2013.

LESKY, A. A tragédia grega. São Paulo: Perspectiva, 1996. 
PASTORE, J. A. D. O trágico: Schopenhauer e Freud. 2012. 381 f. Dissertação (Mestrado em Ciências da Religião) - Pontifícia Universidade Católica de São Paulo. São Paulo, 2012.

PINHEIRO, V. C. O páthos trágico de Aquiles. Revista Archai. v. 7, 87-93, 2011.

Recebido em 22 de fevereiro de 2018.

Aceito em 9 de março de 2018. 